\title{
Staphylococcus aureus carriage state in healthy adult population and phenotypic and genotypic properties of isolated strains
}

\author{
Anna Chmielowiec-Korzeniowska, Leszek Tymczyna, Łukasz Wlazło, Bożena Nowakowicz-Dębek, Beata Trawińska \\ Laboratory of Environmental and Occupational Hazards, University of Life Sciences, Lublin, Poland \\ Adv Dermatol Allergol 2020; XXXVII (2): 184-189 \\ DOI: https://doi.org/10.5114/ada.2020.94837
}

\begin{abstract}
Introduction: At present, infections induced by staphylococci, especially methicillin-resistant Staphylococcus aureus (MRSA) are one of key therapeutic and epidemiological problems.

Aim: The assessment of Staphylococcus aureus carrier state occurrence among a healthy adult population as well as determination of phenotypic and genotypic properties of the isolated strains.

Material and methods: The study included 100 healthy individuals. Material for bacteriological evaluation was collected from the posterior pharyngeal wall and tonsils, nasal vestibule and the skin of anterior nares using a sterile swab. The isolates identified as Staphylococcus aureus were analysed further, towards slime-forming capacity and the presence of genes mecA and nuc.

Results: The analysis included 300 samples obtained from the posterior vault of the pharynx and tonsils, nasal vestibule and the skin of nares. Pharyngeal and vestibular S. aureus carriage was determined in $20 \%$ of the examined adults, whereas in 11 people with recognized positive throat colonization, the concurrent presence of golden staph was detected in the vestibule of the nose and on the skin, in the nose region. Identification process indicated the occurrence of strains defective in clumping factor synthesis (5\% of isolates) and lack of the coa gene (11\% of examined isolates). The PCR technique used to screen for the presence of the mec gene, did not confirm it in any of the strains under study. All the isolates had the gene encoding the thermostable nuclease nuc.

Conclusions: S. aureus is a pervasive pathogen in community settings with constantly changing trends.
\end{abstract}

Key words: Staphylococcus aureus, carriage, polymerase chain reaction.

\section{Introduction}

Over the last decade, Staphylococcus genus has undergone rapid evolutionary changes and as a consequence, highly specialized pathogenic strains, i.e. coagulase-positive Staphylococcus (CPS) and its coagulasenegative counterpart (CNS) developed. Both demonstrate resistance to a number of antibiotics and antimicrobial agents. At present, infections induced by staphylococci, especially methicillin-resistant Staphylococcus aureus (MRSA) are one of key therapeutic and epidemiological problems [1, 2].

Generally, S. aureus makes an asymptomatic constituent of the natural bacterial flora, yet under favourable conditions can cause a number of local infections, mostly involving skin and skin structures (wounds and soft tissues) as well as invasive infections, e.g. pneumonia, osteomyelitis or endocarditis [3]. Particularly severe strains are isolated in hospital settings and may lead to life-threatening conditions, such as sepsis [4, 5].

The recent increase in the incidence of staphylococcal infections has been associated not only with increasing resistance to many common antibiotics (including vancomycin) but prevalent colonization as well. According to Yang et al. [6], colonization favours the maintenance of the microorganism in a population, whereas asymptomatic carriage, especially chronic, serves as a major reservoir for the strain assisting its spread in environment.

It is estimated that 70-90\% of the general population are at least intermittent (transient) carriers of $S$. aureus [7]. Chambers [8] reports that approximately $20 \%$ of the population are persistent carriers, while in about $60 \%$

Address for correspondence: Anna Chmielowiec-Korzeniowska PhD, DSc, Laboratory of Environmental and Occupational Hazards, University of Life Sciences, 13 Akademicka St, 20-950 Lublin, Poland, e-mail: anna.korzeniowska@up.lublin.pl Received: 18.04.2018, accepted: 22.09.2018. 
colonization occurs intermittently. Only $20-30 \%$ of populations are non-carriers who never harbour S. aureus.

Staphylococcus aureus predominantly colonizes the mucous membranes of the upper respiratory tract, including the throat and nose, rarely perineum and anus [9].

Pathogen carriage is associated with individual predisposition of the host and notably, most frequently colonization is acquired by hospitalized patients and in direct contact with healthcare settings $[6,10]$. The main factors predisposing to the staph infection development include age, chronic disease, immunodeficiency and a genetic predisposition [7].

The clinical and epidemiological implications of S. aureus carriage have directed attention towards rapid and accurate microbiological diagnostics. Early identification of carriers is the crucial step in preventing staphylococcal infections. It allows not only for determination of its potential role in the pathological process but also helps identify the potential source of infection thus, prevents reinfection [11].

For decades, identification of $S$. aureus has been based mainly on the evaluation of phenotypic, particularly biochemical and enzymatic characteristics. Nowadays, despite the application of many novel molecular biological techniques, phenotypic identification has still remained the major procedure used in routine microbiological diagnostics [12]. Occurrence of atypical S. aureus strains lacking specific factors, in that coagulase-negative (CNSA) or clumping factor (CFNSA) poses a serious risk for their possible incorrect identification [13]. Hence, genotypic methods are valuable tools of modern diagnostics as they facilitate precise identification of strains and their potential pathogenicity $[14,15]$.

\section{Aim}

The objective of the research was to assess the incidence of Staphylococcus aureus carriage among a healthy adult population and determine phenotypic and genotypic characteristics of the isolated strains.

\section{Material and methods}

The study included 100 healthy individuals aged 2050 years who were evaluated in relation to the incidence of Staphylococcus aureus carriage state in the pharynx, nasal vestibule and the skin of anterior nares. All participants were not hospitalized within the last 3 years, and did not work in the health care service. Exclusion criteria were presence of skin lesions and current use of antibiotics. Each subject filled in a self-completion questionnaire to establish the body condition and hygiene habits. The questionnaire was devised using the following parameters:

1) age and sex;

2) health proneness factor, including:
- incidence of upper respiratory tract disorders, frequency of;

- antibiotic agent use, in that last month;

- incidence of common cold last month;

- skin disorders;

- earlier diagnosed S. aureus in the nose or throat;

3) addiction to nicotine;

4) contact with hospital setting.

Material for bacteriological evaluation was collected from the posterior pharyngeal wall and tonsils, nasal vestibule and the skin of anterior nares using a sterile swab. The obtained material was inoculated into agar solid medium with $5 \%$ sheep blood plates (BioMaxima S.A., Lublin, Poland) and incubated under aerobic conditions for $48 \mathrm{~h}$ at $36 \pm 2^{\circ} \mathrm{C}$ temperature. The isolated microorganisms underwent the macro- and microscopic evaluation. The initial studies included performance of a Gram stain, catalase test and one for the presence of clumping factor CF (Staphylococcus aureus identification test, Biomed, Lublin, Poland). Microorganisms initially classified as Staphylococcus aureus were inoculated onto the Chapman medium and Baird-Parker medium (BTL, Lodz, Poland). After the $24 \mathrm{~h}$-incubation at $36 \pm 2^{\circ} \mathrm{C}$ temperature, they were tested for their ability to degrade lipids and mannitol. The final species-level identification of the cultured strains was made using biochemical tests API Staph (bioMerieux, Inc., Lyon, France). The isolates identified as Staphylococcus aureus were analysed further, including towards slime-forming capacity and the presence of gene mecA and nuc.

\section{Slime-forming capacity}

Studies on the intensity of slime formation in all the Staphylococcus aureus strains isolated were conducted according to Freeman method [15] on the Congo Red Agar (Sigma-Aldrich, Saint Louis, USA). Aerobic incubation was carried out for $48 \mathrm{~h}$ at $36 \pm 2^{\circ} \mathrm{C}$ temperature. The readings were made twice after $24 \mathrm{~h}$ and $48 \mathrm{~h}$ incubation period, taking into account appearance, colour and the intensity of colony colour. The biofilm-producing strains formed dark brown to black colonies of dry crystalline consistency. As for moderate intensity of slime formation, colonies were red-brown with slightly wet surface and finally, the strains that do not produce biofilm constituted light red, wet and a little matt colonies.

\section{Genetic studies}

Isolation of genomic DNA from S. aureus followed the Extractme DNA Bacteria kit protocol (Gdansk, Poland). The research material comprised fresh cultures from the agar medium. The DNA purification protocol consists of 5 steps and utilizes spin minicolumns with membranes that selectively bind nucleic acids. In order to check efficiency of genomic DNA bacteria isolation, the isolation 
Table 1. Number and percentage of identified Staphylococcus aureus as regards isolation site

\begin{tabular}{lccc}
\hline $\begin{array}{l}\text { Sampling } \\
\text { site }\end{array}$ & $\begin{array}{c}\text { Number } \\
\text { of } \\
\text { samples }\end{array}$ & $\begin{array}{c}\text { Number of } \\
\text { Staphylococcus } \\
\text { sp. isolates }\end{array}$ & $\begin{array}{c}\text { Number of } \\
\text { Staphylococcus } \\
\text { aureus isolates }\end{array}$ \\
\hline Pharynx & 100 & $60(100 \%)$ & $24(40 \%)$ \\
\hline $\begin{array}{l}\text { Nasal } \\
\text { vestibule }\end{array}$ & 100 & $64(100 \%)$ & $18(28 \%)$ \\
\hline Nares & 100 & $80(100 \%)$ & $2(2.5 \%)$ \\
\hline Total & 300 & $204(100 \%)$ & $44(22 \%)$ \\
\hline
\end{tabular}

products were separated using agarose gel electrophoresis under standard reaction conditions.

Genotyping of $S$. aureus strains was conducted on the basis of the polymorphism of restriction fragments of the variable region of the coa gene using the commercial diagnostic kit S. aureus Coag made by DNA Gdansk (Poland). The material for examination comprised the previously isolated DNA. Detection was based on amplification of the coa gene fragment. Afterwards, the PCR product obtained was digested using the restriction enzyme of high cutting frequency - Csp61. The amplified fragment was 500-600 bp in size.

Detection of genes mecA and nuc was performed with the assay for genotyping methicillin-resistant strains, S. aureus MRSA-Screen test kit (DNA Gdansk, Poland). Polymnerase chain reaction (PCR) was performed individually for each gene according to the manufac-

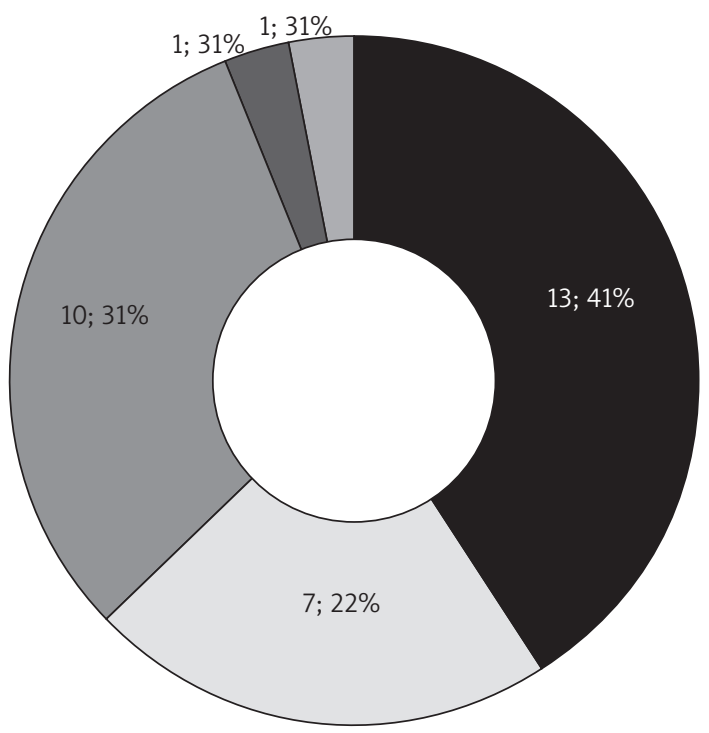

Pharynx

$\square$ Nasal vestibule 口Pharynx and nasal vestibule

Pharynx and nares $\square$ Nasal vestibule and nares

Figure 1. Number of adults with Staphylococcus aureus positive colonization turer's instructions. A standard $25 \mu \mathrm{I}$ PCR reaction mix contained the following components: a pair of primers (1 $\mathrm{\mu M}$ each), concentrated reaction buffer, $4 \mathrm{mM} \mathrm{MgCl}$, $1.6 \mathrm{mM}$ deoxyribonucleotide triphosphates $(0.4 \mathrm{mM}$ each, $0.04 \mathrm{U} / \mu \mathrm{l}$ thermostable DNA polymerases Taq and $1 \mathrm{ng}$ DNA template (target)).

The PCR assay was performed in a thermocycler PTC200 DNA Engine Cycler (BioRad Laboratories Inc., USA) through the following amplification steps: initial denaturation $-1 \mathrm{~min}, 94^{\circ} \mathrm{C}$; denaturation $-30 \mathrm{~s}, 94^{\circ} \mathrm{C}$; primer annealing $-60 \mathrm{~s}, 55^{\circ} \mathrm{C}$; elongation $-60 \mathrm{~s}, 72^{\circ} \mathrm{C}$; final elongation $-4 \mathrm{~min}, 72^{\circ} \mathrm{C}$.

The PCR product underwent agarose gel electrophoresis and after the ethidium bromide staining, the reading was taken. Positive control was indicated for PCR product by its presence at $533 \mathrm{bp}$ in size for the gene mecA and 280 bp for the gene nuc.

\section{Statistical analysis}

The obtained results were tabulated, presenting the number and percentage of the identified isolates. The results of the questionnaire including population health proneness and hygiene habits of the studied subjects were analysed statistically. A Pearson $r$ correlation coefficient was estimated for the binary variables. The analysis was conducted using statistical package Statistica 8.0 (StatSoft Inc. Tulsa, USA).

\section{Results}

A total of 300 samples obtained from the posterior vault of the pharynx and tonsils, nasal vestibule and the skin of anterior nares were analysed (Table 1). The research material served as growth media for 204 Staphylococcus genus strains, in that $S$. aureus was recovered from 32 (32\%) individuals (Figure 1). As many as 24 Staphylococcus isolates originated from the posterior pharyngeal wall. Among 80 strains cultured on the material collected from the anterior nares, $S$. aureus accounted for $2.5 \%$ (Table 1 ).

Staphylococcus aureus carriage in the throat and vestibule of the nose was determined in $20 \%$ of the examined adults (Figure 1), whereas 11 people with recognized positive colonization in the pharynx showed the concurrent presence of staph aureus in the nasal vestibule (10 people) and on the skin in the nose region (1 person). In only one person, the swabs taken from the skin of the nose identified the presence of $S$. aureus. In this case, positive colonization was also established in the nasal vestibule.

Most frequently, S. aureus carriers were patients aged 30.7 (Table 2) and the pathogen was isolated at an equal rate from male and female carriers. Among the respondents, 52 people admitted frequent airway diseases and positive colonization was observed in 16 subjects. Perma- 
Table 2. Questionnaire results with respondents' health proneness factor

\begin{tabular}{lccccc}
\hline Characteristics & Total & S. aureus colonization & \multirow{2}{*}{ r } & P-value \\
& & Negative & Positive & & \\
\hline Number of subjects & $100(100 \%)$ & $68(100 \%)$ & $32(100 \%)$ & - & - \\
\hline Age, mean \pm SD & $32.8 \pm 10.4$ & $33.9 \pm 10.9$ & $30.7 \pm 9.2$ & 0.142 & 0.158 \\
\hline Gender (female) & $55(55 \%)$ & $37(54 \%)$ & $18(56 \%)$ & 0.017 & 0.865 \\
\hline Nicotine addiction & $28(28 \%)$ & $20(29 \%)$ & $8(25 \%)$ & -0.046 & 0.651 \\
\hline Dietary supplementation & $28(28 \%)$ & $19(28 \%)$ & $9(28 \%)$ & 0.002 & 0.985 \\
\hline Frequent incidence of upper respiratory tract diseases & $52(52 \%)$ & $36(53 \%)$ & $16(50 \%)$ & -0.027 & 0.786 \\
\hline Earlier diagnosed pharyngeal S. aureus & $27(27 \%)$ & $19(28 \%)$ & $8(25 \%)$ & -0.031 & 0.760 \\
\hline Earlier diagnosed nasal S. aureus & $17(17 \%)$ & $12(18 \%)$ & $5(16 \%)$ & -0.025 & 0.804 \\
\hline Contact with hospital setting & $15(15 \%)$ & $11(16 \%)$ & $4(13 \%)$ & -0.048 & 0.635 \\
\hline Frequent antibiotic agent use & $27(27 \%)$ & $21(31 \%)$ & $6(19 \%)$ & -0.127 & 0.206 \\
\hline Common colds last month & $25(25 \%)$ & $15(22 \%)$ & $10(31 \%)$ & 0.099 & 0.327 \\
\hline Antibiotic agent used last month & $1(1 \%)$ & $1(1 \%)$ & 0 & -0.069 & 0.495 \\
\hline Skin problems (oily/mixed) & $78(78 \%)$ & $51(75 \%)$ & $27(84 \%)$ & 0.106 & 0.296 \\
\hline
\end{tabular}

Table 3. Characteristics of Staphylococcus aureus isolates

\begin{tabular}{|c|c|c|c|c|c|c|c|c|}
\hline \multirow[t]{2}{*}{ Sampling site } & \multirow{2}{*}{$\begin{array}{l}\text { Number of } \\
\text { subjects }\end{array}$} & \multicolumn{4}{|c|}{ Phenotypic properties } & \multicolumn{3}{|c|}{ Genotypic properties } \\
\hline & & $\begin{array}{c}\text { Lipid } \\
\text { degradation }\end{array}$ & $\begin{array}{c}\text { Mannitol } \\
\text { degradation }\end{array}$ & $\begin{array}{l}\text { Catalase } \\
\text { presence }\end{array}$ & CF factor & Gene nuc & Gene mecA & Gene coa \\
\hline Pharynx & $24(100 \%)$ & $12(50 \%)$ & $24(100 \%)$ & $24(100 \%)$ & $22(92 \%)$ & 24 (100\%) & 0 & $22(92 \%)$ \\
\hline $\begin{array}{l}\text { Nasal } \\
\text { vestibule }\end{array}$ & $18(100 \%)$ & $8(44 \%)$ & $18(100 \%)$ & $18(100 \%)$ & $18(100 \%)$ & $18(100 \%)$ & 0 & $16(89 \%)$ \\
\hline Nares & $2(100 \%)$ & 0 & $2(100 \%)$ & $2(100 \%)$ & $2(100 \%)$ & 2 (100\%) & 0 & $1(50 \%)$ \\
\hline Total & $44(100 \%)$ & $10(23 \%)$ & $44(100 \%)$ & $44(100 \%)$ & $42(95 \%)$ & 44 (100\%) & 0 & 39 (89\%) \\
\hline
\end{tabular}

Table 4. Assessment of slime-formation ability of Staphylococcus aureus strains

\begin{tabular}{lcccc}
\hline Sampling site & Number of subjects & Strong production & Moderate production & No production \\
\hline Pharynx & $24(100 \%)$ & $9(38 \%)$ & $5(21 \%)$ & $10(41 \%)$ \\
\hline Nasal vestibule & $18(100 \%)$ & $8(44 \%)$ & $3(17 \%)$ & $7(39 \%)$ \\
\hline Nares & $2(100 \%)$ & $1(50 \%)$ & $1(50 \%)$ & 0 \\
\hline Total & $44(100 \%)$ & $18(41 \%)$ & $9(20 \%)$ & $17(39 \%)$ \\
\hline
\end{tabular}

nent contact with hospital environment was confirmed by 15 respondents and the rate of $S$. aureus colonization for them was slightly lower. The questionnaire demonstrated that the subjects who claimed overuse of antibiotics accounted for a much lower carriage percentage (19\%) compared to those free from S. aureus. As for recurrent common colds reported over a month preceding the study, 25 respondents complained about it and for 10 of them, the $S$. aureus presence was identified in the swab samples. The statistical analysis performed did not indicate any significant $(p<0.05)$ correlation between the parameters included into the questionnaire and S. aureus colonization.
All the isolates under study degraded mannitol and showed the positive-catalase test result (Table 3 ). Among the isolates recovered from the throat, 2 (8\%) strains lacked clumping factor synthesis as well as the coa gene. The $S$. aureus strains defective in the coa gene were also isolated from the nasal vestibule and the skin. The PCR technology used did not confirm the presence of the mecA gene in any of the investigated strains. All the isolates had thermostable nuclease nuc.

All the strains identified as S. aureus were evaluated for slime-forming ability (Table 4). Among all the studied strains isolated from the collected material, 27 (61\%) isolates showed the capacity to produce biofilm. Consid- 
ering all the bacteria under investigation, the ability to form large amounts of slime applied to $41 \%$ of strains, while 39\% did not produce it at all.

\section{Discussion}

Humans and animals are the primary natural reservoir for S. aureus and an asymptomatic carrier status is reported far more frequently than infections. It can be transient with short-term colonization and no need for therapy or persistent that can last for a couple of months or years. The estimates say that $25-70 \%$ of human population is colonized by Staphylococci $[8,16]$. The present studies have demonstrated that every third adult (32\%) was an asymptomatic carrier of $S$. aureus. The genetic studies excluded the presence of methicillin-resistant strains. Staphylococcus aureus was recovered from the pharynx more often than from the nose or skin. However, Mertz et al. [17] indicate that pharyngeal carriage occurs more rarely and recommend the control of both body sites at routine screening. According to Mainous et al. [18], the frequency of staphylococcal carriage in the nares was $10-45 \%$ and in approximately $3 \%$ of population the MRSA strains were detected.

These results partly agree with the present research ones where $S$. aureus carriage in the vestibule of the nose was determined in $18 \%$ of the examined people, however none of the isolated strains was found methicillinresistant.

Velasco et al. [19] showed that the nasal carriage of S. aureus in healthy people was $7.6 \%$ and, in general, clones were genetically diverse. Similarly to our research, none of the $S$. aureus strains obtained from healthy people were mecA-positive.

Anwar et al. [20], in their studies on 1660 healthy adults, indicated colonization of the upper respiratory tract in $14 \%$ of people, mostly men. While, a percentage of $S$. aureus carriage was inversely proportional to age. The present research did not show such correlations.

The phenotypic and genotypic identification of the isolated strains proved the occurrence of strains defective for clumping factor synthesis (5\% of tested isolates) and the coa gene (11\% of the isolates). The studies by Garbacz et al. [21] conducted in healthcare settings showed that $7.2 \%$ of isolated $S$. aureus strains did not produce coagulase, and $3.8 \%$ were clumping factor CFnegative. This phenomenon may increase ability of the strain to recombinate and as a result, causes lack of some properties typical for $S$. aureus.

The present studies have indicated that as many as $61 \%$ of the isolated $S$. aureus strains produced slime at high or moderate intensity. The obtained results were consistent with those reported by Podbielska et al. [22]. A high percentage of biofilm-producing isolates was also determined by Votava and Woznicowa [23]. Kuthan et al. [24] informed that in their studies, all the isolated staphylococcal strains recovered from the skin, purulent exudate and nasal vestibule swabs exhibited the slimeforming capacity. Smith et al. [25] stated that the strains isolated from the skin surface, as compared to isolates collected from other body sites, had greater capacity to produce biofilms. The slime-generating ability is considered as one of factors enabling Staphylococcus colonization of the organism. The mucous substance surrounding cells facilitates bacterial adhesion to various types of surface, resists drugs and protects against phagocytosis, acts as a chemotaxis and opsonisation inhibitor and finally, induces inflammatory reaction [26].

\section{Conclusions}

It is generally accepted that asymptomatic colonization by $S$. aureus is common and is a prerequisite for the development of staphylococcal infection. The risk of the infection in nasal carriers is estimated to be $2-12$ times higher than in non-colonized persons [27]. Layer et al. [28] report that MSSA can cause infection with the same severity and mortality as MRSA. MSSA has no $\beta$-lactam resistance but can be resistant to other classes of drugs and harbour different virulence genes.

Knowledge about importance and range of $S$. aureus carriage in a society as well as the serious threat posed by multi-resistant microorganisms to patients necessitate development of novel, rapid and efficient diagnostics. The presence of defective staph strains proves enhanced gene expression occurring within a given species and essentially, makes the diagnostics challenging which in turn, hinder bacterial eradication from the environment. In the case of $S$. aureus identification, especially strains of atypical phenotypic characteristics, application of the species-specific PCR should be the optimal solution. The screening tests increase the detection of MRSA and MSSA carriage and, as a result, prevent the pathogen transmission which contributes to a decreased carriage rate of multi-resistant strains in human population.

\section{Conflict of interest}

The authors declare no conflict of interest.

\section{References}

1. Grundmann H, Schouls LM, Aanensen DM, et al. The dynamic changes of dominant clones of Staphylococcus aureus causing bloodstream infections in the European region: results of a second structured survey. Euro Surveill 2014; 19: pii20987.

2. David MZ, Daum RS. Community - associated Methicillin resistant Staphylococcus aureus: epidemiology and clinical consequence of an emerging epidemic. Clin Microbiol Rev 2010; 23: 616-87.

3. Lo WT, Wang CC, Lin WJ, et al. Changes in the nasal colonization with methicillin-resistant Staphylococcus aureus in children: 2004-2009. PLoS One 2010; 5: e15791. 
4. Mathanraj S, Sujatha S, Sivasangeetha K, et al. Screening for methicillin-resistant Staphylococcus aureus carriers among patients and health care workers of a tertiary care hospital in south India. Indian J Med Microbiol 2010; 27: 62-4.

5. Trafny E. Relatively pathogenic intracellular bacteria in infections of the upper respiratory tract and the ear. Postep Mikrobiol 2012; 51: 277-90.

6. Yang ES, Tan J, Eells S, et al. Body site colonization in patients with community-associated methicillin-resistant Staphylococcus aureus and other types of S. aureus skin infections. Clin Microbiol Infect 2010; 16: 425-31.

7. Hasse-Cieślińska M. Staphylococcus aureus skin colonization in atopic dermatitis patients. Post Dermatol Alergol 2007; 24: 107-15.

8. Chambers HF. The changing epidemiology of Staphylococcus aureus. Emerg Infect Dis 2001; 7: 178-82.

9. Nouwen J, Boelens H, van Belkum A, et al. Human factor in Staphylococcus aureus nasal carriage. Infect Immun 2004; 72: 6685-88.

10. Klevens RM, Morrison MA, Nadle J, et al. Active bacterial core surveillance, M.I. Invasive methicillin-resistant Staphylococcus aureus infections in the United States. J Amer Med Assoc 2007; 298: 1763-71.

11. Międzobrodzki J, Małachowa N, Markiewski T, et al. Differentiation of isolates of Staphylococcus aureus on the basis of phenotypic characteristics. Postepy Hig Med Dosw 2008; 62: 322-7.

12. Garbacz K, Galiński J. Atypical Staphylococcus aureus strains defective in coagulase or clumping factor (CF). Postep Mikrobiol 2006; 45: 39-43.

13. Lévesque S, Bourgault AM, Galarneau LA, et al. Molecular epidemiology and antimicrobial susceptibility profiles of methicillin-resistant Staphylococcus aureus blood culture isolates: results of the Quebec Provincial Surveillance Programme. Epidemiol Infect 2015; 143: 1511-8.

14. Collery MM, Smyth DS, Twohig JM, et al. Molecular typing of nasal carriage isolates of Staphylococcus aureus from an Irish university student population based on toxin gene PCR, agr locus types and multiple locus, variable number tandem repeat analysis. J Microb 2008; 57: 348-58.

15. Freeman DJ, Falkiner FR, Keane CT. New method for detecting slime production by coagulase negative staphylococci. J Clin Pathol 1989; 42: 872-4.

16. Peacock SJ, de Silva I, Lowy FD. What determines nasal carriage of Staphylococcus aureus? Trends Microbiol 2001; 9: 605-10.

17. Mertz D, Frei R, Jaussi B, et al. Throat swabs are necessary to reliably detect carriers of Staphylococcus aureus. Clin Infect Dis 2007; 45: 475-7.

18. Mainous AG, Hueston W, Everett C. Nasal carriage of methicillin-resistant S. aureus in United States, 2001-2002. Ann Fam Mewd 2006; 4: 132-7.

19. Velasco V, Buyukcangaz E, Sherwood JS, et al. Characterization of Staphylococcus aureus from humans and a comparison with isolates of animal origin, in North Dakota, United States. PLoS One 2015; 10: e0140497.

20. Anwar MS, Jaffery G, Rehman Bhatti KU, et al. Staphylococcus aureus and MRSA nasal carriage in general population. J Coll Physicians Surg Pak 2004; 14: 661-4.

21. Garbacz K, Piechowicz L, Wiśniewska K, et al. Characteristics of defective MRSA strains which do not produce coagulase or factor CF. Med Dosw Mikrobiol 2002; 54: 1-8.

22. Podbielska A, Gałkowska H, Stelmach E, et al. Slime production by Staphylococcus aureus and Staphylococcus epi- dermidis strains isolated from patients with diabetic foot ulcers. Arch Immunol Ther Exp 2010; 58: 321-4.

23. Votava M, Woznicowa V. Production of smile by staphylococcal isolates from blood cultures. Cent Eur J Public Health 2000; 8: 18-20.

24. Kuthan RT, Łuczak M, Młynarczyk G. Production the biofilm by methicillin-resistant strains of Staphylococcus aureus. Post Nauk Med 2011; 10: 862-8.

25. Smith TC, Male MJ, Harper AL, et al. Methicillin-resistant Staphylococcus aureus (MRSA) strain ST398 is present in midwestern U.S. swine and swine workers. PLoS One 2009; 4: e4258.

26. Szymankiewicz M, Janicka G, Wróblewska J. Wytwarzanie śluzu przez szczepy Staphylococcus aureus pochodzace z materiałów klinicznych. Pol Merkuriusz Lek 2004; 17: 338 40.

27. Simor AE. Staphylococcal decolonisation: an effective strategy for prevention of infection? Lancet Infect Dis 2011; 11: 952-62.

28. Layer F, Ghebremedhin B, König W, et al. Heterogeneity of methicillin-susceptible Staphylococcus aureus strains at a German university hospital implicates the circulatingstrain pool as a potential source of emerging methicillinresistant S. aureus clones. J Clin Microbiol 2006; 44: 2179-85. 